\title{
FUERO DE ADSCRIPCION POR JAIME II DE LAS VILLAS DE ORIHUELA Y ALICANTE A LA CORONA DE ARAGON
}

Por

JUAN MANUEL DEL ESTAL 
A comienzos del año 1277, la crisis dinástica que estallara en Castilla a raíz de la muerte imprevista del infante don Fernando de la Cerda, heredero del trono (1275), condujo a su viuda, doña Blanca de Francia, a buscar asilo político en la corte de Aragón y solicitar de su cuñado, Pedro III el Grande, la protección necesaria para sus dos hijos, Alfonso y Fernando de la Cerda (1).

Le preocupaba seriamente la seguridad de sus vidas, toda vez que el segundogénito de Alfonso $\mathrm{X}$ el Sabio, el infante don Sancho, aspiraba en exclusiva al trono castellano y en las cortes de Segovia, convocadas por su padre el 1276, se había hecho prestar pleito-homenaje y jurar solemnemente por príncipe heredero de Castilla (2).

(1) Desclot, Bernat: Llibre del rei en Pere, c. LXXVI (ed. Ferrán Soldevila, «Les quatre grans cròniques», Barcelona, 1971, pág. 465); ZURITA, Jerónimo: Anales de la Corona de Aragón, lib. IV, c. III (ed. preparada por A. Canellas López, t. 2, Zaragoza, 1970, págs. 15-17); "Crónica del rey don Alfonso X", caps. LXVII y LXVIII (ed. Bibl. Autores Españoles, t. LXVI, «Crónicas de los reyes de Castilla», I, Ma. drid, 1953, págs. 52.53). Un historiador moderno comenta así el suceso: *el 8 de gener de 1277 Blanca de França vidua de l'infant Ferran, el primogènit del rei va fugir de Castella amb els seus fills Alfons i Ferran, els princeps coneguts amb el sobrenom dels infants de la Cerda, els hereus legals de Corona de Castellan, F. Soldevila: Vida de Pere el Gran (Barcelona, 1963), pág. 138.

(2) aLlegado el rey a la cibdad de Segovia, vinieron y los infantes é los maestres é todos los ricos omes é infanzones e caballeros é villas de los sus reinos. E el rey mandóles que ficiesen pleito é omenaje al infante don Sancho su fijo, primero heredero, que despues de dias del rey don Alfonso que le oviesen por 
Temerosa asimismo la reina madre, doña Violante, esposa del Rey Sabio, de la suerte que pudieran correr sus nietos de la Cerda, tras los sucesos referidos, se afanó por sacarlos cuanto antes de los dominios castellanos y ponerlos a salvo en los aragoneses de su hermano, Pedro el Grande, según nos relata la crónica castellana: aE despues estos pleitos é omenajes fueron fechos, la reina doña Violante, mujer de este rey don Alfonso, envió sus cartas al rey don Pedro de Aragón, su hermano, en que le envió decir los pleitos que los del reino avian fecho al infante don Sancho, é ella por esto quería ir fablar con él, é que llevaria consigo á don Alfonso é a don Fernando. E salió la reina de Segovia é con ella doña Blanca, é levaron consigo aquellos don Alfonso é don Fernando; é pasaron el puerto, é fueron á... Hariza, que es en el reino de Aragón, é el rey don Pedro vino é levólos consigo á Calatayud" (3).

Pedro III el Grande se daba perfecta cuenta de la excelente baza política que le suponía la retención de sus dos ilustres primos en tierras de Aragón, disponiendo aposentar a tan singulares rehenes en el castillo de Játiva (4), en espera de encontrar en ellos buenos valedores para un mayor medro de su política peninsular (5).

su rey é por su señor é todos ficieron lo que les el rey mandón, Crónica del rey don Alfonso X, c. LXViIII, pág. 53.

(3) Ibidem.

(4) Doña Violante regresó a su reino de Castilla el año 1278. aE despues que ella fue venida, el rey don Pedro de Aragón mandó tomar a don Alfonso é a don Fernando, fijos del infante don Ferrando é de doña Blanca, é pusiéronlos en el castillo de Játiva, do estuvieron presos en toda su vida deste rey don Pedro ( +1285$)$. E doña Blanca, madre destos don Alfonso é don Ferrando, desque los vió en prisión, estuvo un poco de ticmpo en Aragón en un monasterio de dueñas é despues salió de allí é fuese para Franciap a la corte de su hermano, Felipe III ael Atrevidò (Crónica de Alfonso X, c. LXXI, pág. 55).

(5) DescLoT, LXVI, págs. 465-466; ZURITA, lib. IV, caps. III, VI, VIII, X y XII, páginas 26, 29-31, 37 y 41. Los catalano-aragoneses no habían olvidado aún la cesión gratuita por Jaime I el Conquistador de todo el Reino de Murcia a la Corona de Castilla, a raíz de su ocupación en 1265, ni querían aceptar pasivamente que acuando todavía existían en la Península tierras sarracenas por rescatar, toda acción expansiva (peninsular) hubiese terminado para ellos» (F. Soldevilu: Historia de España, t. II, Barcelona, 1972, 3.' ed., pág. 9). 
La ocasión esperada se la brindó la violación castellana de los acuerdos firmados en las vistas de Campillo y Agreda, entre el Rey Sabio y. Pedro III, en 1281 (6), en beneficio de la mutua paz y estrecha alianza contra todo agresor, así como la negociación francocastellana con $\mathrm{Fe}$ lipe III el Atrevido, contra la Corona de Aragón (7).

La represalia aragonesa, como era lógico, no se hizo esperar. El propio Muntaner nos señala que esta felonía indujo a Pedro el Grande a re. nunciar al mando personal de la expedición armada a Baleares y confiarla a su hijo, el infante don Alfonso de Aragón, para ocuparse directamente de la entronización de Alfonso de la Cerda en el trono de Castilla, aunque la muerte (1285) no le permitió verla lograda (8). Sus dos hijos y sucesores, Alfonso III y Jaime II, persistirian en el empeño, que describimos a continuación.

El primero, en efecto, hizo jurar solemnemente en Jaca a don Alfondo de la Cerda por rey y señor de Castilla, en el ootño de 1288. El cronista Zurita nos refiere así el suceso: «Estaba el rey de Aragón en la ciudad de Jaca por el estío de 1288 y mandó llevar a su corte a don Alonso y don Fernando, hijos del infante don Fernando, con propósito de favorecer a don Alfonso en la guerra que se le ofrecía por el derecho de los reinos de Castilla y León... Era el principio del mes

(6) Durante los días 27 y 28 de marzo. Desclot, LXXVI, págs. 464-466; ZuRITA, lib. IV, c. XI, págs. 38-40.

(7) 'ZuRITA, lib. IV, c. XI y XII, págs. 38-40; c. XXXV, págs. 127-129; c. LIX, páginas 211-213; Soldevila: Historia de España, t. II, págs. 11 y 12.

(8) Crónica, c. CLVI, págs. 810-811. Nos reláta así el suceso, poniendo en boca de su hijo y sucesor, Alfonso III ael Liberal», la siguiente evocación: a...nostre pare, lo rei En Pere, partí de Barcelona ab cor e ab volontat que si Déu l'aportàs sa e saul en València, que havia en cor de trer de Xàtiva los fills de l'infant En Forrando de Castella é que volia fer rei de Castella don Alfonso, lo major, per ço que es venjàs de son nebot lo rei En Sanxo de Castella qui tan gran falla li havia feta (alusión manifiesta a la traición apuntada); qui al major obs que ell havia, li fallí de tot quant li era tengut (infracción de lo pactado en las vistas de Campillo y Agreda). E pus a Dèu no ha plagut que ell en sa vida no se n'és pogut venjar, nós lo devem venjar... E nos irem e'l regne de València e traurem aquells infants de Xativa, e aplegarem nostres hosts, e ab ells ensems entrarem en Castella, e farem tant que ells sien reis de Castella, ab l'ajuda de nostre senyor ver Dèus Jesucrist, qui al dret ajudaràn, ibid. 
de septiembre cuando estando juntos en Jaca, con gran solemnidad y fiesta, don Diego Lope de Haro y muchos ricos hombres y caballeros de Castilla alzaron y juraron por rey y señor de los reinos de Castilla y León a don Alonso y le besaron la mano, haciéndose sus vasallos; y tomó el nombre y apellido del rey con las armas $e$ insignias reales. $\mathrm{Y}$ de allí adelante el rey de Aragón y todos los príncipes de aquella liga le llamaron e intitularon rey" (9), confederándose para defender juntos su causa.

Al propio tiempo, el rey de Aragón hizo llegar despachos a los más significados ricos hombres y caballeros de Castilla para invitarles a tomar las armas contra Sancho IV el Bravo, en favor de su sobrino don Alfonso de la Cerda, prometiéndoles en recompensa amplios beneficios y mercedes (10), por la postura adoptada ya desde tiempos de Alfonso $\mathrm{X}$ el Sabio en resuelto apoyo a la causa de los descendientes del infante de la Cerda, motivo por el que el Rey Sabio los privara de sus beneficios y rentas feudales. A su vez, se obligaba el rey de Aragón a uque se les cumplirian cualesquiera privilegios y gracias que les concediese don Alonsow (11), constituido ya rey. Con ello se proponía Alfonso III el Liberal captarse el favor de la nobleza castellana, descontenta contra su soberano por los desafueros referidos, y atraerla más fácilmente hacia su pupilo (12).

El gesto de gratitud por parte de Alfonso de la Cerda no se hizo esperar hacia su homónimo, el soberano de Aragón, al que hacía donación, en un acuerdo secreto, firmado en Calatayud, a 26 de junio de 1289, de todo el Reino de Murcia (13).

(9) Anales, lib. IV, c. CIII, págs. 357-359.

(10) Mediante la devolución integra de los beneficios enajenados, años atrás, sobre todo ade las villas y rentas que hubiesen tenido aquéllos a quienes se quitaron en tiempo del rey don Alonso ( $\mathrm{X}$ el Sabio) su agüelo de la misma suerte que las poseyeron y gozaron en su vidan, ZURITA, lib. $v$, c. CV, pág. 366.

(11) Cuando hubiese ceñido la corona de Castilla. Ibid.

(12) Ansiosa de nuevas mercedes. Ibid.

(13) a...considerando don Alonso (de la Cerda) que el rey de Aragón era el que hacía la guerra a su enemigo con toda su pujanza y que sin su ayuda por otra 
Un año antes, temeroso ya Sancho IV de que el apoyo aragonés a su sobrino don Alfonso de la Cerda pudiera elevarlo al trono de Castilla y privarlo a él consiguientemente del mismo, llegó a ofrecer al monarca de Aragón la mano de su hija, la infanta Isabel, con la dote tentadora del reino de Murcia, a cambio de la extradición de sus rivales, los dos hijos de su hermano, el infante de la Cerda (14). Proposición a la que no quiso ni pudo acceder naturalmente Alfonso III para no traicionar la inocencia de sus regios rehenes (15), y exponer a una muerte y eliminación segura a auns infants innocents» (16).

La confrontación armada se hizo inevitable entre Castilla y Aragón por este motivo: «E el rey don Sancho... fizo hacer muy cruda guerra en el reino de Aragón, matando, robando, quemando, cortando las olivas e los árboles, é poniendo fuero a toda la tierra...é dió consigo más adentro del reino de Aragón, faciendo la más cruda guerra que pudos (17), por el mes de abril de 1289.

Por su parte, el rey de Aragón «se n'anà a Xàtiva, e tragué del castell de Xàtiva don Alfonso e don Ferrando, fills de l'enfant En Ferrando de Castella, e feu aparellar moltes gents de cavall e de peu ab que pogués entrar ell'd'una part, en Castella ab don Alfonso, e que d'altra

via no podría salir con aquella empresa y que en ella ponia su persona y estado. en reconocimiento desto hizo al rey de Aragon donación del Reino de Murcia Cartagena... y esto se hizo con gran secretos, ZuRITA: Anales, lib. IV, c. CIX, páginas 375-376.

(14) Debió tener lugar esta negociación por mayo de 1288, ZuRITA, lib. IV, c. C; Ludwig KLUPFel: Die Aussere Politik Alfons III. Von Aragonien (Berlín-Leipzig, 1911-1912), doc. $\mathrm{V}$.

(15) Sobreques Vidal, S.: Alfons el Franc (Els descendents de Pere el Gran: \&Biografies catalanes», VI), Barcelona, 1968, p. 34 y nota 139.

(16) Soldevilla, F.: Vida de Pere el Gran I D'Alfons el Liberal, Biblioteca Biográfica Aedos, 35 (Barcelona, 1963), págs. 336-337.

(17) Cronica del rey don Sancho IV el Bravo, aBiblioteca de Autores Espa. nolesso, t. LXVI, pág. 81, donde data así el suceso: «En el mes de Abril... en mill é doscientos é ochenta y nueve años», ibid., pág. 80; MuNTaNer: Crònica, c. CLVIII, páginas 812-813; Zurita: Anales, lib. IV, caps. C, CIII, CV y CIX; Soldevilla: História de Catalumya (Barcelona, 1962, 2: ed.). I, pág. 384; GaIBro is DE Ballesteros, Mercedes: Historia del reino de Sancho IV (Madrid, 1928), I, pág. 214. 
part entràs l'infant En Pere» (18), con el propósito de hacer proclamar rey de Castilla a don Alfonso de la Cerda, lo que habría conseguido, de buen seguro, escribe Muntaner, de no haber tenido que abandonar la frontera castellana, para acudir a defender la Cerdaña contra la intrusión armada de Jaime de Mallorca (19).

De todas formas, unos días antes de su partida para el Rosellón, quiso Alfonso de la Cerda recompensar al monarca aragonés la ayuda incomparable que venía prestando a su causa, con la donación en secreto del Reino de Murcia, el 26 de junio de aquel mismo año (20) y asegurarse de este modo su apoyo incondicional por el interés que ello reportaba a la Corona de Aragón (21).

Con esta donación quedaba ya integrado a la Corona de Aragón, si bien de una manera nominal y de jure, el Reino de Murcia (22), que

(18) Muntaner: Crònica, c. CLVIII, pág. 812. Por este tiempo Alfonso III el Liberal retenía a sus ilustres rehenes no ya en Játiva, sino en Morella: $\alpha$ No és de Xàtiva, sinó de Morella que el rei Alfons va fer treure els infants de la Cerdaw (SoldEviLA, R.: Les quatre grans cròniques, Barcelona, 1971, nota 2 a este capitulo CLVIII de la Crònica de Muntaner, pág. 973). S. Sobreoues Vidal añade que los descendientes del infante don Fernando de la Cerda estaban retenidos en Morella desde el año anterior, de donde se los llevó a Jaca en el otoño de 1288 para proclamar al mayor, don Alfonso, arei de Castella a presència de molts refu. ghats castellans», Alfons el Franc (Els descendents de Pere el Gran) (Barcelona, 1968), 3." ed., pág. 35.

(19) aE segurament que en aquell cas ell (Alfonso el Liberal) hagra tolta tota la terra al rei don Sanxo, sinó que li venc missatge d'Empordà... (con las noticias del levantamiento del Rosellón y Mallorca). E així lo senyor rei, per açó, hac-se eixir de Castella» con dirección a Zaragoza y Barcelona (MuNTaner: Crónica, c. CLVIII, a fines de junio de 1289).

(20) V. nota 13.

(21) Apostilla así el hecho un gran conocedor de este periodo: aNo fou per amor i generositat que Alfons (de Aragón) va ajudar els infants de la Cerda. El 26 de juny, a Calatayud, Alfons de la Cerda li va a cedir secretament el regne de Múrcian, Soldevila: Crónica de MunTaner, c. CLVIII en Les quatre grans croniques, pág. 974, nota 5, y en otra obra añade el mismo autor: aMúrcia era el justificant de tota l'actuacció del rei Alfons en aquesta qüestió dels infants castellans. La recuperación, en suma, de aquellas tierras del Reino de Murcia era el eje de toda su politica territorial y apoyo a don Alfonso de la Cerda, donante de las mismas a la Corona de Aragón; KıUPFel: 0 . c., caps. IX y X.

(22) SOLdevila: História de Catalunya, I, pág. 384: Alfonso III el Liberal *...desprès d'haver reintegrat al trono catalano-aragonès les Balears, reunia també 
Jaime II, su hermano, siete años después, conseguiría incorporarlo de facto el 1296.

Fiel a lo pactado, este monarca prosiguió la misma política territorial que sus dos antecesores, Pedro III el Grande y Alfonso III el $\mathbf{~ L i}$ beral. Apenas hubo ceñido la corona (24 septiembre 1291), "vino entonces a verle don Alonso, hijo del infante don Fernando (de la Cerda), que se intitulaba rey de Castilla, por asentar nueva amistad y liga con él, con las condiciones que tenía firmadas con el rey don Alonso (III el Liberal), su hermano, para que juntos prosiguiesen su empresa contra el rey de Castilla», Sancho el Bravo (23).

El rey de Castilla ensayó una vez más su vieja política de alianzas matrimoniales con el nuevo soberano aragonés, ofreciéndole la mano de su hija, la infanta Isabel, en las 'Capitulaciones' y 'Concordias' celebradas en Monteagudo, el 29 de noviembre de aquel mismo año, con la dote tan tentadora del Reino de Murcia, igual que hiciera cuatro años antes con su hermano Alfonso III (24), y de momento con éxito mayor, ya que «Dos días después ... en Soria ... se hicieron los deposorios estando presentes el rey don Sancho y la reina doña María (de Molina), un sábado, primero del mes de deciembre deste año» (25), contando la infanta nueve años de edad.

Pero la deslealtad de Sancho el Bravo a lo convenido en la 'Concordia' de Monteagudo y sus negociaciones secretas con el rey francés, encami-

als seus regnes les terres murcianes, també separades de fet per la politica poc afortunada de l'avi", Jaime I el Conquistador, cuando renunciara al Reino de Murcia a favor de su yerno, Alfonso X el Sabio, el 1265 .

(23) ZuRITa: Anales, lib. IV, c. CXXIV, pág. 422.

(24) V. supra, nota 14 y el texto correspondiente.

(25) Zurita, lib. IV, c. CXXIV pág. 424; amplio relato sobre el particular, ibid., caps. CXXIV-CXXVI, págs. 422429; Crónica del rey don Sancho IV, c. IX, página 86: «E de sí (Medina del Campo) fue el rey don Sancho verse con el rey de Aragón a tierra de Soria, é puso su pleito con él, é diole su fija la infanta doña Isabel que entraba en nueve años; é el rey de Aragón tomóla por mujer, puso pleito de casar con ella cuando ella oviese doce años conplidos, é desto dio castillos en rehenes, é demás puso con el rey don Sancho de le dar once galeras armadas para aquella guerra de los moros». 
nadas a recabar su ayuda contra Aragón (26), en el curso de 1293, indujeron a Jaime II a rescindir la 'Concordia' citada y a solicitar del Papa la declaración de invalidez de su compromiso matrimonial con la infanta de Castilla, en razón del impedimento existente de consaguinidad entre ambos, en tercer grado, del que no se había requerido previamente ninguna dispensa pontificia (27). La reapertura de hostilidades entre Castilla y Aragón fue el resultado inmediato, con repercusión favorable en la causa de don Alonso de la Cerda, que lograba interesar nuevamente al soberano aragonés en sus reivindicaciones dinásticas a la corona de Castilla, a cambio de la donación del Reino de Murcia.

La crisis sucesoria desencadenada a la muerte de Sancho IV el Bravo (25 abril 1295), con la impugnación de la legitimidad de su heredero, Fernando IV el Emplazado, por el infante don Juan, su propio tío paterno (28), brindaba a Jaime II nueva ocasión para desarrollar su política territorial expansionista por las tierras castellanas del Reino de Murcia, cedidas formalmente años antes por don Alfonso de la Cerda.

El 24 de junio de aquel mismo año sancionaba públicamente en la catedral de Anagni el Papa Bonifacio VIII la concordia estipulada, ante su presencia, por los embajadores del rey de Francia, el de Aragón y del rey de Nápoles, Carlos II de Valois, cuya hija, la infanta doña Blanca, entregada en matrimonio a Jaime II en aquella ocasión, sellaba

(26) Zuritas Anales, lib. V, c. VII, págs. 449-452.

(27) Ibid., c. XI, pág. 467.

(28) Hijo también de Alfonso $X$ el Sabio, basaba su impugnación en que los progenitores del nuevo rey de Castilla, don Sancho IV el Bravo y doña Maria de Molina, eran aparientes en grado prohibido y no haber precedido dispensa apostólica, como se requerías según los cánones. ZuRITA, lib. V, c. XX, pág. 493; Crónica del rey don Fernando IV. c. I, pág. 93: a...e estadndo (la reina madre, doña María de Molina) en Toledo llególe mandado de cómmo el infante don Juan, que era en Granada, que se queria llamar rey de los reinos de Castilla e de León, é que quería venir a la tierra con gran poder de los morosw. 
esta paz francoaragonesa y comprometía a sus firmantes a secundar las aspiraciones dinástico-sucesorias de Alfonso de la Cerda (29).

Este, por su parte, no descuidó un momento el reasegurarse la ayuda ofrecida por el rey de Aragón, tornando a reiterarle en Bordalba (Ariza), a principios del año siguiente, la consabida donación del Reino de Murcia, al objeto de vincularlo más estrechamente a su causa (30).

Apenas dos semanas después, disponiéndose Jaime II a iniciar la campaña de ocupación del Reino de Murcia, tornaba de nuevo don Alfonso a hacerle entrega y donación del mismo, por tercera vez, en la villa de Serón, a 4 de febrero de 1296 (31).

El rey de Aragón se hacía entregar allí previamente, de manos del de la Cerda, “los instrumentos de los homenajes que los naturales deste reino le habían hecho y los recaudos necesarios para que todos le obedeciesen por rey" (32), con el propósito de asegurarse formalmente la adhesión de los concejos más importantes.

Nos han llegado a este efecto varias actas municipales, mereciendo destacarse, entre otras, las de Elche (33) y Orihuela (34), donde se proclama uper lur senyor natural et per rey del Regne de Murcia al molt

(29) Zurita: Anales, lib. V, c. V, págs. 459-466; MaRTinez Firrando, J. E.: Jaime II o el Seny Catalá (Barcelona, 1963, 2.' ed.), c. IX, «La pau d'Anagni», páginas $115 \cdot 122$.

(30) a...hallándose don Alonso, hijo del infante don Fernando (de la Cerda) que se llamaba rey de Castilla y León a 21 del mes de enero deste año (1296) en Bordalba, aldea de Hariza, se concordó con el rey don Jaime y se obligó el rey de ayudarle y valerle en la guerra contra el rey de Castilla (Fernando IV). Y por esta causa don Alonso le hizo donación del reino de Murcian, ZURITA, lib. V. c. XX, pág. 495.

(31) Ibid.

(32) Ibid., c. XXI, pág. 499.

(33) a...fecha en Ëlche, çinco dias de agosto era de mill et treçientos et treynta et quatro annos», año 1296, pergamino del acta notarial concejil, publicada por Juan TORRES FONTES: Colección de documentos para la historia del Reino de Murcia, II. Documentos del siglo XIII (CODOM II), Murcia, 1969, doc. CXXI, pág. 124.

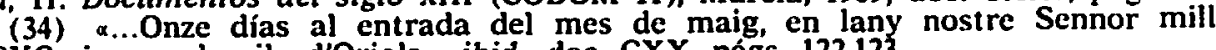
CCXC sis... en la vila d’Oriolas, ibid., doc. CXX, págs. 122-123. 
alt poderos senyor En Jacme (II el Justo), por la gracia de Deu, rey d'Aragó... per rao de la donatio al dit senyor rey En Jacme feita purament et entre vius per lo molt alt senyor Namfos (Alfonso de la Cerda), per la gracia de Deu, rey de Castella.... (35).

Con anterioridad se había ocupado ya don Alfonso de la Cerda de expedir cartas a los referidos municipios del Reino de Murcia, ordenán. doles su más fiel adhesión al rey aragonés. Sirva de ejemplo fehaciente la que destinó al concejo de Orihuela, fechada en Serón a 3 de febrero de 1296, de la que extractamos lo que sigue: a...vos mandamos, escribe, al concejo e a los homes buenos de orihuela, que obedeçcades al dicho senyor rey de Aragon é a los suyos é lo tengades é lo ayades por senyor verdader é natural é les respondades con todos los drechos é quales quier otras raçones que a nos erades tenudos de responder é non a otro ninguno. E nos absoluemos é quitamos uos de toda fe jura homenage fealdat é naturaleza que a nos fuesedes tenudo. ( $\mathrm{Y}$ en líneas anteriores razonaba la orden por la que le mandaba obedecer al soberano de Aragón.) Commo nos ayamos dado el regno de Murcia con todos sus terminos e sus pertenençias asi como a nos perteneçe é lo auer deuemos por qualquier manera por nuestras cartas seelladas con nuestra bulla de plomo colgada al muy noble don Jaymes por la gracia de dios rey de Aragon por las muchas é grandes ayudas é grandes plaçeres é en muchas de maneras que recibiemos de sus antecesores por la qual donacion que nos le facemos non entendemos quel podemos gradecer complidamente asi como a el perteneçe é segund las aiudas que de los suyos auemos tomado asi como dicho es...» (36).

(35) Acta notarial del concejo de Orihuela, ya citada. Ibid., pág. 122.

(36) Libro becerro de privilegios reales, fol. $9 \mathrm{v}-10 \mathrm{r}$. Archivo Municipal de Orihuela, MS, núm. 2588. En un Apéndice documental, que insertamos al final del trabajo, ofrecemos la transcripción de esta Carta Donación de don Alfonso de la Cerda, con el núm. 1. Fue ya publicada anteriormente por MARTíNEz MoRELLA, V.: Cartas de los reyes de Castilla a Orihuela, 1265-1295 (Alicante, 1954), p. 87; TorkEs Fontes, J.: Colección de documentos para la historia del Reino de Murcia, II. Documentos del siglo XIII (Murcia, 1969), doc. CXVI, págs. 118-119. Ambos autores tomaron el texto de otro códice posterior del Archivo Histórico Nacional de Madrid, núm. $1368 \mathrm{~B}$. 
En la primavera de aquel mismo año 1296, Jaime II emprendía personalmente la conquista y ocupación de las tierras del Reino de Murcia, logrando someter, a mediados de abril, el empinado y casi inexpugnable castillo de Alicante, defendido con el sacrificio de su vida por su alcaide castellano, don Nicolás Pérez de Murcia (37).

De allí se dirigió a Guardamar, Almoradí y Orihuela, que conquistó en abril y mayo, y después pasó a Elche, a la que puso sitio el día 10 y el «11 del mes de julio se le dio un muy recio combate» (38), que se prolongó por espacio de dos semanas más, al cabo de las cuales capitulaba el noble don Juan Manuel, en cuyo nombre firmaban dos lugartenientes suyos, Gómez Ferrández y Alfonso García, una tregua de siete años con el rey de Aragón, al que reconocían su señor natural y se declaraban vasallos suyos, hasta que su señor cumpliese los 21 años de edad, por contar entonces tan sólo 14, y pudiese prestar a Jaime II vasallaje y reconocerlo como «señor y rey del Reino de Murcia» (39), llegado a la mayor edad. Extractamos estos extremos: "Sepan cuantos esta carta vieren, que ante nos don Jayme... rey de Aragón... estando en el sitio de Elch con nuestra gente, vinieron los honrados Gómez Ferrández y Alfonso García, consejeros y procuradores del noble don Juan (Manuel), hijo del noble infante don Manuel que fue ( $\dagger$ 1284), relatándonos los grandes y buenos servicios de que nos es deudor el dicho don Juan y su edad que ahora tiene (14 años solamente) y nos queriendo aquellos buenos deudos guardar... aviniéndonos con ellos en nombre de don Juan... a saber:

1. Que os damos... todas las tierras de nuestro señorío y todos los

(37) Muntaner: Crònica, c. CLXXXVIII, págs. 834-835; Torres FonTes, J.: Nicolás Pérez, alcaide de Alicante (Murcia, 1964). Durante la elaboración de este trabajo pudimos comprobar el error cronístico de MUNTANER y ZURITA, con referencia al asedio y conquista por Jaime II de Aragón de las plazas de Alicante, Orihuela, Guardamar y Elche, debiendo anteponerlas, algunas de ellas, en más de dos meses, según se desprende de la atenta lectura de los Registros de Gracia de este soberano, como pudimos demostrar en un artículo enviado a la revista Item, num. 2, 1977, págs. 99-109, de la Facultad de Filosofía y Letras de Alicante.

(38) Zurita: Anales, lib. V, c. XXI, pág. 500.

(39) Ibid. 
lugares y villas y castillos que... don Juan tiene en el reino de Murcia (40), desde hoy (hasta que cumpla don Juan Manuel los 21 años, quedando ellos responsabilizados en el interim de su gobierno y administración, bajo la soberanía de Aragón)...

7. Otorgamos y prometemos que si cuando Juan fuere de edad de veinte años y después de un año primero avenidero o antes si él quisierc reconociera a nos por señor y por Rey del Reino de Murcia e hiciese aquellas cosas que es costumbre hacer y debe hacer al señor y rey del dicho Reino de Murcia, nos le rendremos Elch con todos sus términos, el puerto y todos los otros lugares sobredichos, bien y cumplidamente libres y quitos, con todos sus derechos y con todas las obras y mejoras...

8. Queremos... que la villa de Elch quede en este fuero en que agora está... Declaramos que no se quebrante la tregua Y y de esto nosotros Gómez Ferrández y Alfonso García, que reciben de vos, señor Rey... la tregua, en nombre y voz del dicho don Juan, damos por él y en voz y nombre suyo a vos señor rey de Aragón Don Jayme tregua duradera por el tiempo sobredicho por don Juan... de todos los lugares que... tiene en el Reino de Murcia... en buena fe y sin engaño. Y prometemos que no hará guerra ni mal ni consentirá que se haga a las ciudades villas castillos y otros lugares que agora señor rey de Aragón teneis o tengais... en el Reino de Murcia... Dada en el sitio de Elche, a 27 días del mes de julio del año mill doscientos noventa y seis» (41).

Siete años después, en efecto, Jaime II devolvía el señorío de Elche y sus términos a don Juan Manuel, a cambio del reconocimiento de la jurisdicción soberana sobre el mismo del rey de Aragón (42).

(40) Elche y su puerto de Santa Pola, Monóvar, Elda, Novelda, Monforte, Axpe, Petrel, La Muela, Crevillente, Favanilla, Callosa de Segura y Guardamar, v. ZuRI53. lib. V, c. XXI, págs. 499-500; MUNTANER, c. CLXXXVIII, pág. 835.

(41) Reproducción del texto integro por A. Rasios Folques: Historia de Elche (Elche, 1970), págs. 109.113 y Jiménez Soler, A.: D. Juan Manuel, 1932, doc. VII, páginas 228-231.

(42) La cuestión del deslinde y fijación de fronteras entre los Reinos de Valencia y Murcia originaria sucesivamente serias desavenencias entre Castilla $y$ 
Con anterioridad a la firma de las treguas de Elche, prosiguió su expedición Jaime II hacia la parte meridional del Reino de Murcia, recibiendo, sin lucha, de manos de su alcaide castellano, don Pedro Ruiz de San Cebrián, la villa y fuerte castillo de Orihuela, en los primeros días de mayo del mismo año: «E puis hac Oriola e lo castell, que li reté Pero Roís de Sant Cebrià, qui n'era alcaid, que el li reté con vée que la vila d'Oriola hac haüda; e hac gran raon que li retés lo castell sens colps e senes costada, que un dels pus forts castells e dels pus reials és d'Espanya" (43). Recuérdese cómo el rey de Aragón, antes de iniciar la conquista de este reino castellano, se hizo entregar por don Alfonso de la Cerda, tenido allí por su legítimo rey y señor natural, las cartas 'plomadas' de donación del mismo (44). Extractamos algunos puntos del acta de adhesión del concejo de Orihuela, firmada el 11 de mayo de 1296: "Coneguda cosa sia als presents com als esdevenidors... en presencia de mí Pere de Lemynyana, notari publich de Oriola... et en Jacme Cabde. bou, tenent loch del Exemen Enegis... Apellat et ajustat consell... en la eglesia de Sent Saluador, otorgants et reconoxents tuit ensems a la vniversitat justada en la eglesia damunt dita, per lur senyor natural et per rey del regne de Murcia lo molt alt et poderos senyor en Jacme, por la gracia de Deu, rey d'Aragó... segons que es contengut en carta publica de la dita donatio (del senyor Namfos - de la Cerda- rey de Castella...), bollada ab bolla de plom de aquell senyor rey Namfos, la qual carta los

Aragón, durante casi una década, siendo resueltas finalmente en Torrellas, agosto de 1304, por la «Sentencia Arbitral» de este nombre, «lugar apacible a las faldas del Moncayo», pronunciada por el rey de Portugal, don Dionís, por el infante don Juan, hermano de Sancho IV el Bravo, en representación dé Castilla, y por don Ximeno de Luna, obispo de Zaragoza, en nombre de los intereses de Aragón, los tres constituidos en jueces árbitros de tan enojoso asunto fronterizo. Véase Zurita, lib. V, c. LXVI, págs. 667-670; Muntaner: Crònica, c. CCXLV. Para una exposición documental más amplia sobre este problema litigioso, v. J.-M. DEL EsTAL: Problema sucesorio de Castilla y anexión de Alicante a la Corona de Aragón. Comunicación leída en las Jornadas de Estudios Medievales, celebradas en Ciudad Real, con ocasión del VII Centenario de la muerte del infante don Fernando de la Cerda, heredero de Castilla, 2-6 de abril de 1975, v. VII Centenario del Infante don Fernando de la Cerda, Ciudad Real, 1976, págs. 237-263.

(43) Muntaner: Crònica, c. CLXXXVIII, pág. 835. Del. Estal: Item, 2, 1977, páginas 101-103.

(44) V. supra notas $32-35$ con su texto correspondiente. 
homens de la dita vniversitat veren et fo en la dita esglesia lesta et mostrada a ells (29 jurados y consejeros)... Et aut sobre les coses damunt dites acort et diligent tratat feren homenatge de boca et de mans al damunt dit senyor rey en Jacme, axi com a senyor lur natural et $a$ rey de Murcia et del regne, del qual regne es la dita vila d'Oriola ab sos termens et $\mathrm{ab}$ ses pertinenties. Et promesseren a bona fe tots los damunt dits... que... seran al dit senyor en Jacme et als seus succesors fels homens et vasalls et defendran ell... ab la vila de Oriola contra totes persones axi com lur rey et senyor natural» (45), reconociéndose, en consecuencia, pleno jure vasallos del rey de Aragón.

Muy pocos días bastaron a este soberano para someter a su corona todo el Reino de Murcia, ya que acometió la culminación final de su empresa reconquistadora "con tanta furia, escribe un cronista, que el dos de agosto se había ya el rey apoderado de Murcia y a 18 siguiente estaba en Valencian (46), del año 1296, dejando en aquél, en condición de Procurador y Gobernador a su hermano natural, don Jaime Pérez de Exérica, señor de Segorbe (47).

Del tiempo que tenía puesto el sitio a la villa de Elche, data el privilegio real que transcribimos: "Datum in obsidione Elchij, decimo calendas augusti, anno Domini millesimo ducentesimo sexto» (48), correspondiente al 23 de julio de 1296. Se trata de un traslado notarial en pergamino, compuesto por orden del Justicia de la villa de Alicante, don An-

(45) Texto publicado por J. ToRres FonTEs: Codom II, doc. CXX, págs. 122-123.

(46) ZURITA, lib. V, c. XXI, pág. 500 . Véase lo referido supra en las notas 37 y 47.

(47) a...e lleixà hi per procurador lo noble En Jacme Perez, sou frare, ab molta bona cavalleria que hi lleixà ab ell; venc-se'n (Jaime II) al Regne de Va. lència» Muntaner, ibid.

La fecha del asedio y conquista de Murcia no es tampoco la consignada por el cronista MuNTaNer, que la sitúa en el mes de agosto, sino tres meses antes, exactamente el 18 de mayo de 1296, como puede verse corroborado por la aportación documental sobre el tema en otro trabajo nuestro: Dos cartas-privilegio inéditas de Alfonso $X$ el Sabio y Jaime II de Aragón respectivamente a favor de la villa de Orihuela. Años 1281 y 1296», en ltem, núm. 3, 1979, págs. 73-86, y particularmente en las notas 15 y 21 .

(48) Arch. Municipal de Alicantc, A. 16, Cax. 1, núm. 1. Privilegio inédito. Ofrecemos la transcripción en Apéndice núm. 2. 
drés de Sena, por el notario público y escribano del Consejo municipal de dicha villa, Matheu Ferrer, que lo escribió de su puño y letra y comprobó con el original palabra por palabra 'feelment mot a mot comprouj', y lleva el refrendo protocolario del notario público de la villa de Alicante y escribano del palacio y corte del referido Justicia, Petro Codinus, que redactó de su puño la autoridad y decreto del Justicia, legitimando este traslado, y lo dató puntillosamente: miércoles "Dimecres, denou dies de Juny, any de la nativitat de nostre senyor myl quatrecents trenta e set» (49).

Por este fuero dispone Jaime II la incorporación de la villa de Alicante a la Corona de Aragón de modo perpetuo: a....nos Jacobus dei gratia rex Aragonum etc. volentes castrum et vilam de Alacant semper in nostro et nostrorum dominio permaneren (50), expresando su voluntad de no permitir jamás, bajo ningún concepto, su ulterior división y separación: "...convenimus et bona fide promitimus quod nos et omnes successores nostros vobis universis et singulis hominibus de Alacant... quod numquam causa aliqua vel ratione separabimus seu dividemus nec separari seu dividi faciemus consentiemus seu permitemus» (51), proscribiendo a su vez todo acto de compraventa, enajenación o donación, pública o privada, directa o indirecta, a ningún precio: a...et quod numquam de dicto loco donationem, venditionem permutationem seu cambium vel aliquam aliam alienationem quoquo titulo sive modo faciemus consencieumus seu fieri permitemus palam vel oculte directe vel indirecte» (52), comprometiéndose además, con juramento solemne (53), a no desprenderse en lo sucesivo la Corona de Aragón nunca jamás de la villa de Alicante: «...immo locum predictum cum omnibus suis terminis in nostro et nostrorum successorum regni Aragonum dominio et regimine tenebimus et conseruauimus in perpetuum" (54).

(49) Ibid.

(50) Ibid.

(51) a...a corona regni Aragonie et a dominio nostron, ibid.

(52) Ibid.

(53) v...promittimus et bona fide ac sub virtute per nos vobis prestiti in fide iuramentiv, ibid.

(54) Ibid. 
Añade a continuación el monarca aragonés su firme compromiso con la villa de Alicante de guardar y hacer cumplir escrupulosamente cuanto antecede, sin dolo ni engaño, para su mayor bienestar y desarrollo, en perfecta inteligencia con la corona: a...predicta autem omnia et singula promittimus... vobis predictis hominibus dicti loci de Alacant... tenere atendere et complere atque inuiolabiter obseruari absque omni dolo et fraude... ad uestrum uestrorumque saluamentum et bonum intellectums (55).

Acompañan al escatocolo final de este "presens priuilegium»(56) del rey Jaime II las firmas de altos funcionarios de la nobleza catalanoaragonesa, en condición de testigos calificados, cinco en total, por este orden: «Guillem de Angelaria (57) o de Anglesola, caballero catalán (58); «Raymundus Fulconis vicecomes Cardone» (59) o Ramón Folc o Folch, vizconde de Cardona (60); "Jaspertus vicecomes de Castro novo" (61) o Jasbert, vizconde de Castellnóu, alto dignatario catalán en la corte aragonesa (62); «Jacobus de Xerica» (63) o Jaime Pérez de Xérica y Señor de Segorbe, hijo bastardo de Pedro III el Grande y hermanastro consi-

(55) Ibid.

(56) Privilegio de Jaime II a la villa de Alicantc, Arch. Municipal de Alicantc, A. 16, Cax. 1 , núm. 1.

(57) Ibid.

(58) Martinez Ferrando, J. E.: Jaime II o el Selly Català (Barcelona, 1963, 2." ed.), pág. 309.

(59) Ibid. El autor de este traslado, Matheu Ferrer, al añadir equivocadamente al título nobiliario - comes - de este testigo el nombre del siguiente - Jaspertus-. priva de su topónimo correspondicntc a Ramón Folch - vice comes Cardone- y se lo adjudica equivocadamente al segundo, descomponiéndole el suyo propio: «vice comes de Castro novon, al interponer erróneamente entre de Castro y novo el título comes Cardone, correspondiente al anterior. El orden correcto del texto debe ser, pues, éste: aRaymundus Fulconis vice comes Cardone, Jaspertus vice comes de Castro notion. El autor fue aqui victima simplemente de un error de transposición literaria.

(60) Martínez Firrando: O. c., passim; Soldevilla, F.: Vida de Pere el Gran I Alfons el Liberal (Barcelona, 1963), págs. 250-252.

(61) Arch. Mun. de Alic., A. 16, Cax. 1, núm. 1. Téngase presente la rectificación anotada anteriormente, not. 59 .

(62) SOldevila: $O$. c., págs. 32 y 40; Lee Sh Eidman: L'Imperi Catalano-Aragonés (1200-1350) (Barcelona, 1975), t. I. págs. 270, 310; II, pág. 61.

(63) Ibid. 
guientemente de Jaime II de Aragón (64) y, por último, "Raymundus Cor. tauinyo» (65) o Ramón Arnal de Cortavinyó (66), ilustre barón catalán.

Siguen finalmente en el privilegio real los nombres del Justicia «de la vila de Alacant, en Andreu de Sena» (67), que legitimó con su firma y autoridad el presente traslado notarial; el del escribano de su palacio y corte, don Pedro Codinus, notario público de la villa de Alicante (68); $y$, en último lugar, el de Matheu Ferrer, escribano del Consejo municipal y notario público de la referida villa (69), con la datación precisa del traslado, a 19 del mes de junio, miércoles, del año 1437.

En el mismo año que el privilegio anterior, con una antelación de casi dos meses y medio, extendió Jaime II otro privilegio, de contenido enteramente similar al de Alicante, a favor ahora de la villa y concejo de Orihuela: "Datum Oriole quinto idus madij, anno Domini millesimo ducentesimo nonagesimo sexton (70), a 11 de mayo de 1296, por el que se comprometía, en términos idénticos, a reconocerla del dominio pleno de Aragón y a mantenerla unida por siempre a la corona: «Noverint uniuersi quod nos Jacobus dei gratia Rex Aragonum... afectantes villam et castrum de Oriola semper in nostro et nostrorum dominio remanere et etiam retinere» (71), y a no permitir jamás su ulterior separación, cambio o enajenación, bajo ningún motivo: "Conuenimus et bona fide promittimus per nos et omnes successores nostros... vobis uniuersis et singulis hominibus de Oriola... quod numquam casu aliquo separabimus villam et castrum de Oriola nec separari faciemus consenciemus

(64) Martinez Ferrando: Jaume $I I$, pág. 151.

(65) Ibid.

(66) LEE SheIdmaN: $O$. c., págs. 131-132, donde da también la grafía: Ramón Arnold de Cortavinyó.

(67) Ibid.

(68) «...qui de manament del dit honorabl Justice lo present decret e auctoritat scriui de la mia manon. Ibid.

(69) Y ejecutor material de este traslado: a...lo qual dit tresllat scriui e aquel be e feelment mot a mot comprouy e acloy ab loch dia e anny damunt dits», ibid.

(70) Libro becerro de privilegios reales de Orihtela, Arch. Municipal de Orihuela, Ms. núm. 2588, fols. 17 r-17 v.; véase lo referido supra nota 37.

(71) Ibid., fol. $17 \mathrm{r}$. 
aut permittemus a corona regni Aragonum et dominio nostro... immo... tenebimus et conseruabimus in eternum» (72).

Con un escatocolo idéntico al privilegio de Alicante, éste de la villa de Orihuela aparece corroborado por los testigos siguientes cualificados: «Testes sunt Raymundus Fulconis» (73), Guillelmus de Angelaria (74), Sanctius de Antillon» (75) o de Antilló, aJacobus de Xerica» (76), «Petrus Martini de Luna" (77), dignatarios todos ellos egregios en la corte catalano-aragonesa. En el Apéndice documental damos también su transcrip. ción, tomada de un Registro de Jaime II (78).

En un traslado posterior de principios del siglo xv (79) se reproduce nuevamente el texto de este privilegio a favor de Orihuela, legitimado ahora por el Justicia de la villa, cuyo nombre, texto formulario y rúbrica correspondiente faltan en el pergamino tan mal parado.

También dos notarios públicos, uno de la villa y corte del justicia de Orihuela, don Guillén de Moterernes (82), consignó la autoridad del justicia de su puño y letra: «qui de mandato dicti honorabilis justicie in hoc transcumpto propria manu mea suam auctoritatem et decretum aposui et scripsi vicesima prima madii, anno a nativitate domini M.CCCC.XVII" (83), y el otro, "Pere Graçia per auctoritat real notar

(72) Ibid., fol. $17 \mathrm{v}$.

(73) Ya conocido, v. supra nota 60.

(74) También conocido, v. supra nota 58.

(75) Un testigo nuevo, distinguido barón catalán y conde de Urgel. Soldevila: Les quatre grans Cròniques, págs. 625, 631 y 1006; LEE S HEIDMAN: $O$. c., t. I, pág. 81. (76) V. supra nota 64 y texto correspondiente.

(77) Pedro Martínez de Luna, noble aragonés y alto funcionario de la corte, v Soldevila: Les quatre grans Cròniques, págs. 351, 386-387 y 1167.

(78) ACA (Arch. Corona de Aragón), Reg. Grat. 194, fol. 236 v-237 r. Consúltese en el Apéndice documental el texto núm. III.

(79) Traslado en pergamino, mutilado en dos tercios de su parte superior, sin inventariar y carente de toda signatura, guardado en el Archivo Municipal de Orihuela.

(81) V. facsímil adjunto.

(82) aSignum mei Guilleimi de Moterernes notarii publici ville Oriole et scribc Curie predicte villen, ibid.

(83) Ibid. 
publich dela villa d'Oriola e de partida del Regne de Valencia de Sexona ença e scriua del dit honorabl Consell dela dita vila d'Oriola qui lo dit trasllat del dit priuilegi que es en la sala del dit Consell trascriui e scriui e ab aquel lealment lo comrpoue e acloy ab loch dia e anny damunt dits» (84), redactó materialmente este traslado y lo comprobó lealmente con el original, que se guardaba en la sala del concejo de Orihuela todavia por aquellas fechas.

Tras una larga exploración de los fondos manuscritos del archivo municipal de la villa de Orihuela, hallamos otro traslado más tardío del mismo privilegio, en un códice del siglo xv (85), en mejor estado de conservación, y que coincide literalmente con la transcripción que ofrecemos del Registro Gratiarum de Jaime II, 194, en el Apéndice documental, con el número III.

Con uno y otro fuero, analizados hasta aquí a favor de las villas de Orihuela y Alicante, emanados por Jaime II el 11 de mayo y 23 de julio respectivamente de 1296 , iniciaba el soberano aragonés una política territorial de anexión a su corona de las tierras del reino de Murcia, que culminaría formalmente con la incorporación oficial de su sector norte al Reino de Valencia, el año 1308 (86).

(84) Ibid.

(85) Libro becerro de privilegios reales de Orihuela, Archivo Municipal de Orihuela, Ms. núm. 2588, fols. 17 r-17 v. También está inédito.

Deseamos aprovechar la oportunidad que nos brinda este punto de referencia documental para agradecer muy encarecidamente a la autoridad local de esta ciudad y a los funcionarios del Archivo Municipal referido a las facilidades y servicios que tan generosamente han sabido dispensarnos a lo largo de la consulta reiterada del mismo.

(86) Tema que reservamos de propósito para otro estudio monográfico más amplio, que tenemos ya muy avanzado. 


\section{APENDICE DOCUMENTAL}

I

Carta-donación de don Alfonso de la Cerda al concejo de Orihuela notificándole la donación del Reino de Murcia a Jaime II, rey de Aragón, urgiéndole por ello entera obediencia y sumisión al mismo, como a su señor natural. (Libro Becerro de privilegios reales de Orihuela. Archivo Municipal de Orihuela. Ms. n. 2588 , fol. 9 v-10 r.).

Don Alfonso por la gracia de dios Rey de Casticlla e de Toledo, de / León, de Gallicia, de Sevilia, de Cordoua, de Jahen e de Algarbe,/al Conceio e a los ommes buenos de Orihuela Salut / como a naturales que amamos e en qui fiamos. Commo nos ayamos / dado el Reyno de Murcia con todos sus terminos e ses pertenencias / asi commo a nos perteneçe e lo auer deuemos por qualquier / manera por nuestras cartas seelladas con nuestra bulla de plomo colgada, / al muy noble don Jayme por la gracia de dios Rey de Aragon por / las muchas e grandes ayudas e grandes plaçeres e en muchas / de maneras que recibiemos de sus antedesores por la qual donacion / que nos le facemos non entendemos quel podemos grade/cer complidamente asi como a el perteneçe e segun las ayudas / que de los suyos auemos tomado asi como dicho es. Decimos uos / espresamente uos mandamos que obedeçcades al dicho senyor/Rey de Ara gon e a los suyos e lo tengades e lo ayades por senyor/uerdadero e natural e le respondades con todos los drechos / e qualesquier otras raçones que a nos erades tenudos de respon/der e non a otro ninguno. $\mathrm{E}$ nos absoluemos e quitamos uos de toda / fe, jura, homenage, fealdat $\mathrm{e}$ naturaleça que a nos fuesedes / tenudo. Dada en Seron tres dias de fe brero Era de mil e trescientos / XXXVIIII annyos. (Año 1296). Yo Aparicio Pereç por mandado del / Rey la escriui /. 
Traslado notarial en pergamino del diploma de Jaime II fechado en el asedio de Elche a 23 de julio de 1296, a favor de la villa de Alicante, proscribiendo su secesión de la Corona del Reino de Aragón. (Archivo Municipal de Alicante. Arm. 16, Cax. 1, n. 1.)

Aço es trasllat be e feelment pres e traslladat en Alacant a denou dies del mes de Juny en lany dela nativitat de nostre senyor M CCCC / Trenta Set de un altre transllat autentich de hun priuilegi otorgat ala dita vila dalacant per lo molt alt senyor Rey en / Jacme lo qual ni alguna part de aquell no appar esser dapnat cancellat o veciat la tenor del qual priuilegi es segons se seguex. / Altre transllat be e feelment translladat dun priuilegi del dit senyor Rey ab sagell seu de cera pendent sagellat la tenor / de qual es aytal.

In christi nomine. Nouerint uniuersi quod nos Jacobus dei gracia Rex Aragonum etc. volentes castrum et vila de Alacant / semper in nostro et nostrorum dominio retinere conuenimus et bona fide promitimus per nos et omnes succesores nostros vobis unieursis et singulis hominibus de Alacant presentibus et futuris quod nunquam casu aliquo uel ratione separabimus seu dividemus nec separari seu diuidi faciemus consenciemus seu permitemus / a Corona regi Aragone et a dominio nostro et quod nunquam de dicto loco donationem venditionem permutationem seu cambium vel aliquam aliam alie / nationem quoquo titulo siue modo faciemus consenciemus seu fieri permitemus palam uel oculte directe vel indirecte immo locum predictum cum omnibus / suis terminis in nostro et nostrorum successorum regni Aragonum doninio et regimine tenebimus et conseruabimus in perpetuum predicta autem omnia et singula/promitimus et bona fide ac sub uirtute per nos vobis prestiti in fide juramenti conuenimus vobis predictis hominibus dicti loci de Alacant presentibus et / futuris tenere atendere et complere atque inuiolabiliter obseruari absque omni dolo et fraude sicut melius dici et 
inlelligi potest ad vestrum / vestrorumque saluamentum et bonum intellectum Et ad hec omnia tenenda complenda et obseruanda heredes et successores nostros in Regno Ara/gone teneri volumus ac etiam obligari. Et ut hec omnia et singula majorem in omnibus obtineant firmitatem juramus per deum et eius / santa quator euangelia manibus nostris corporaliter tacta quod predicta omnia et singula vobis et vestris obseruabimus et faciemus inuiola / biliter obseruari ac non contraueniemus per nos uel per aliquam interpositam personam aliquo jure causa uel ratione in cuius rey testimonium et ad / eternam rey memoriam presens priuilegium nostrum fieri jusimus sigilla nostri munimine roborari. Data in obsidione Elchij X Kalendas / augusti Anno domini M CC XC sexto. sigillada. Signum (monograma regio de Jaime II) Jacobi dei gracia rex Aragonum Majorice Valencie et Murcie ac Comes Barchinone. / Testes sunt Guillem de Anglaria R (aymundus) Fulconis vice Jaspertus de Castro Comes Cardona nouo Jacobus de Xerica A(rnaldus) Corcauinyo. Signum Petri / (signo notarial) Luppeti scriptoris dicti domini regis qui mandato eiusdem hec scribi fecit et clausit loco die et anno prefixis. (signum)./

S (signo) enyal del honrat en Andreu de Sena Justicia dela Vila de Alacant qui vist lo present Jnstrument e priuiletgi la nostra Auctoritat e de / cret prestam atorgam e donam (subscriptio). /

Sen (signo notarial) yal de $\mathrm{mj}$ Petro Codjnus notari publich dela Vila de Alacant e scriua de la Cort del honorable Justicia de la dita Vila/qui de manament del dit honorabl Justice lo present decret e autoritat scriuj dela mja mano. Djmecres denou dies / de Juny any dela nativitat de nostre senyor myl quatrecents trenta e set e cloy ab loch dies e any damunt dits (subscripción)./

Sen (signo notarial) yal demy Matheu Febrer notari publich dela vila dalacant scriua del honorable consell dela dita Vila dala / cant quyvist lo original priuilegi o transllat autentich de aquell donu lo present transllat que stat pres e / translladat lo qual es en la sala del dit consell dela dita Vila lo qual dit transllat scriuj e aquel be e / feelment mot a mot comprouj e acloy ab loch dia e any damunt dits (subscripción)./ 
ACA, Reg. Grat. 340 Murcie, fol. 279 v. En confirmación de cuanto queda dicho, nota 59, transcribimos lo referente a los firmantes: "Testes sunt: Raymundus Fulchonis vicecomes Cardone, Jacobus de Exericha, Jaspertus de Castronouo, Guillelmus de Angularia, Arnaldus de Corçanino». Por lo demás, el texto del Registro es idéntico al transcrito de la copia notarial que damos.

\section{III}

Orihuela, 11 mayo 1296.-Privilegio de Jaime II a la villa de Orihuela proscribiendo toda secesión de la Corona. (Transcripción del texto, tomado del Reg. Grat. 194, fol. 236 v-237 r, ACA.)

\section{VILLE D'ORIOLA}

Nouerint uniuersi quod nos Jacobus etc. Affectantes villam et castrum d'Oriola semper in nostro et nostrorum dominio / permanece ac etiam retinere, conuenimus et bona fide promitimus per nos et omnes successores nostros uobis unieuersis et $\sin /$ gulis hominibus de Oriola et terminorum eius presentibus et futuris quod nunquam casu aliquo separabimus villam et castrum / de Oriola nec separari faciemus aut permitemus a Corona Regni Aragonum et dominio nostro / et Regni predicti et quod de predictis villa et castro de Oriola nullam donationem uenditionem permutationem / (237r) seu concambium vel aliquam aliam alienationem inde faciemus consentiemus seu etiam permitemus palam vel occulte, directe / uel indirecte. Immo villam et castrum d'Oriola cum suis terminis predictis in nostro ac nostrorum successorum Regni Arago / nie dominio ac regimine tenebimus et obseruabimus in eternum. Predicta autem omnia et singula promitimus et bona fide et sub / uirtute per nos uobis prestiti juramenti vonuenimus uobis predictis hominibus presentibus et futuris attendere et complere ac in / uiolabiliter obseruare absque omni dolo et fraude, sicut melius dici et intelligi et excogitari potest ad bonum et sanum ac sincerum/intellectum nostri et nostrorum. Et 
heredes ac successores nosotros in Regno Aragonie ad hec omnia supradicta et singula seruanda / uobis et uestris teneri uolumus et specialiter obligamus. et ut predicta majori gaudeant firmitate juramus per deum et eius sanc/ta IIII Euangelia propriis manibus nostris corporaliter tacta quod predicta omnia et singula uobis et uestris obseruabimus et complebimus / et faciemus obseruari inuiolabiliter et compleri. In cuius rei testimonium presens priuilegium nostrum sigilli nostri pen / dentis munimine fecimus roborari. Datum Oriole V Idus Madii, anno domini millesimo ducentesimo nonagesimo sexto.

Signum Jacobi dei gratia etc.

Testes sunt

Raimundus Fulchonis

Guillelmus de Angelaria

\author{
Sanctius de Anti de Antilione \\ Jacobus de Xerica \\ Petrus Martini de Luna
}

Se guarda copia también de esta provisión real de Jaime II de Aragón: "De non separanda villa d'Oriola a Corona Aragonum» en un Libro becerro de privilegios reales del Arch. Munic. de Orihuela, Ms. 2588, fol. 17 $y$ otra en AHN, Ms. 1368 B, fol. 38 v - 39 r. 